\title{
INOVAÇÃO E EMPREENDEDORISMO: POLÍTICAS PÚBLICAS E AÇÕES PRIVADAS
}

http://dx.doi.org/10.25091/

Solo1-3300201700030004
CARLOS TORRES Freire*

FELIPE MASSAMI MARUYAMA**

MARCO POLLI***

\section{RESUMO}

O artigo examina a importância crescente do empreendedorismo nos processos de inovação no século XXI. As startups ocupam tal papel pelo seu dinamismo no desenvolvimento tecnológico, com inovações que transformam setores da economia, e por sua capacidade de lidar com conhecimento específico e novo. Isso aparece na expansão e diversificação de programas públicos de apoio às startups em diferentes países e na ampliação de ações de grandes empresas em busca de articulação com empresas iniciantes inovadoras.

PALAVRAS-CHAVE: inovação; empreendedorismo; políticas públicas.

\section{Innovation and Entrepreneurship: Public Policies and Private Actions ABSTRACT}

The article examines the growing importance of entrepreneurship in innovation processes in the $21^{\text {st }}$ century. Startups play this role for their dynamism in technological development, with innovations that transform economic sectors, and for their ability to deal with specific and new knowledge. This appears both in the expansion and diversification of public programs to support startups in different countries and in the expansion of large companies actions in order to collaborate with innovative startups.

KEYWORDS: innovation; entrepreneurship;publicpolicies.

[*] Centro Brasileiro de Análise e Planejamento, São Paulo, SP, Brasil.

E-mail:catorresfreire@usp.br.

$\left.{ }^{[* *}\right]$ Prefeitura de São Paulo, São Paulo, SP, Brasil. E-mail: fmaruyama $@$ prefeitura.sp.gov.br.

[***] Financiadora de Estudos e Projetos, São Paulo, SP, Brasil. E-mail: mpolli@finep.gov.br.

\section{MUDANÇAS NO CONTEXTO DA INOVAÇÃO NO SÉCULO XXI: REDES, EMPREENDEDORISMO E STARTUPS}

A Revolução da Tecnologia da Informação a partir dos anos 1970 leva a mudanças significativas nas formas de produzir bens e serviços, nos modelos de negócio e no desenvolvimento tecnológico, seja com o maior peso na produção, no armazenamento e na utilização de informação, seja no papel de catalisadora da convergência de áreas de conhecimento e atividades econômicas, como nanotecnologia, biotecnologia e inteligência artificial. São parte desse contexto a globalização produtiva no fim do século XX, com uma nova divisão internacional do trabalho e o aumento da mobilidade dos trabalhadores, e 
a descentralização da produção de conhecimento em instituições de ciência e tecnologia e empresas em diferentes partes do mundo.

Utilizando aqui um recurso de estilização do contexto da inovação no século XX, seria possível simplificar e descrevê-lo como um processo de certo modo fechado, realizado por grandes empresas, com seus laboratórios internos de pesquisa e desenvolvimento (P\&D), caracterizado por ciclos longos de desenvolvimento de produtos, com necessidade de grande aporte de recursos próprios ou públicos, mediante encomendas estratégicas e financiamentos ou subsídios robustos.

Já a inovação na virada do século e principalmente nesta segunda década do XXI se diversifica e apresenta uma articulação mais complexa. Além dos componentes já citados, que continuam presentes, principalmente a necessidade de grandes investimentos, a análise da inovação revela a presença de outras características, que tornam o fenômeno mais complexo: maior participação de empresas emergentes; maior presença de projetos de médio e curto prazos; financiamento compartilhado, seja do Estado (que sempre existiu com força, mas ganha novos formatos), seja de grandes empresas em direção a outros atores, como pequenas empresas ou instituições de ciência e tecnologia; e organização em rede e maior interação entre diferentes atores (clientes, fornecedores, instituições de ciência e tecnologia, startups), com variados formatos, que culminam no que alguns autores chamam de inovação aberta. ${ }^{1}$

O fenômeno da inovação no século XXI parece, portanto, apresentar novas dinâmicas. A primeira que merece menção talvez seja a dinâmica que agrega novas tendências, seja a inovação se consolidando como um esforço em rede, por meio da colaboração constante de uma empresa principal com fornecedores, clientes, empresas parceiras, grandes e pequenas, e instituições de ciência e tecnologia tanto para aprendizagem como para compartilhamento de custos e de riscos.

A segunda que merece destaque é o fato de que as tradicionais inovações de produto, de processo ou organizacionais ganham a companhia de novas bases de inovação que não se encaixam devidamente nessas categorias. Por exemplo, novas formas de entrega de serviços e de captura de valor, como usos de novos canais de distribuição ou fontes de receita, podem ser tão ou mais relevantes em termos de transformação do sistema produtivo, como é o caso da inovação em modelos de negócio. ${ }^{2}$ Um exemplo seria o Netflix, que primeiramente introduziu um serviço de distribuição de DVDs por correio vinculado a uma assinatura de baixo valor, passando ao streaming de conteúdo pela internet, também por assinatura. Em ambos os casos houve uma combinação nova de canal de distribuição e forma de cobrança para o entretenimento audiovisual. 3 Sabemos hoje sobre o sucesso do segundo caso, dada a disseminação do uso do serviço.
[1] No nível mais fundamental, a noção de inovação aberta se baseia no fato de que as fontes de conhecimento estão distribuídas na economia. Chesbrough (2003; 2006) dissemina o conceito de inovação aberta ao descrever o fenômeno das empresas que fazem uso maior em seus negócios de ideias e tecnologias externas (e mesmo as internas de áreas diferentes do departamento comumente responsável por pesquisa e desenvolvimento ou inovação). A inovação aberta seria um processo baseado em fluxos de conhecimento gerenciados nas fronteiras organizacionais utilizando diferentes mecanismos. Um processo mais poroso e aberto, que exige das organizações novas práticas para lidar com tal abertura (Chesbrough, 2003; 2006; Gassmann; Enkel, 2004; Dahlander; Gann, 2010; West; Bogers, 2014; Vanhaverbeke; Chesbrough; 2014).

[2] Osterwalder; Pigneur, 2011.

[3] Keating, 2013 . 
[4] Ries, 2010.

[5] Lardinois, 2016 .

[6] Spender et al., 2017; Mason; Brown, 2013. O conceito de ecossistema empreendedor e de inovação se inspira em autores da economia regional e da inovação e da geografia econômica, que tratam da aglomeração de atores e da importância de fatores institucionais, culturais e sociais para o desenvolvimento econômico, especialmente no que se refere a atividades mais intensivas em conhecimento, como Saxenian (1994), Storper (1997), Malmberg e Maskell (1997), Lundvall (2007) e Storper e Venables (2004).

[7] OECD, 2013 .

[8] Torres-Freire; Maruyama; Polli, 2017.
Em terceiro lugar, por conta da difusão das tecnologias de informação e da maior oferta de capital de risco, as pequenas empresas passam a ser mais capazes de liderar inovações de caráter disruptivo, as quais exploram oportunidades tecnológicas e de negócios para transformar e criar novos mercados. Muitas vezes essas empresas nem mesmo possuem os ativos tangíveis próprios do negócio, como são os casos do Uber, que presta serviços de transporte sem possuirveículos, ou do Airbnb, que presta serviços de alojamento sem a propriedade de quartos.

Por fim, vale dizer que o desenvolvimento de novos produtos e serviços se aproveitam de novas abordagens de interação com usuários em ciclos curtos, introduzindo-se assim a possibilidade de um produto mínimo viável e do aperfeiçoamento por meio do uso. ${ }^{4} \mathrm{O}$ Google tem feito isso com frequência, tendo como caso mais emblemático o Gmail, que permaneceu disponível em status beta, sendo testado em uso, de 2004 a 2009 , e atualmenteé o serviço de webmail mais usado no mundo. 5

As startups, que podem ser vistas como a materialização da junção entre empreendedorismo e inovação, foco deste artigo, são parte dessa mudança significativa na dinâmica dos processos de inovação, marcada por maior diversificação de mecanismos e atores envolvidos. Elas representam novos atores dentro do que foi definido na literatura como "ecossistema de inovação", 6 são desenvolvedoras de novos produtos, processos e modelos de negócios e centrais na criação de valor. Sua presença influencia também o modus operandi das empresas estabelecidas, tanto pela ameaça de competição direta ou transformação radical do mercado como pelas oportunidades de parcerias para o desenvolvimento tecnológico. Características como agilidade, renovação constante da base produtiva e capacidade de aglutinar recursos humanos qualificados tornaram esse modelo de empreendimento bastante relevante nas novas dinâmicas de inovação.

Por sua vez, a definição de startups não é consensual. Existem duas grandes linhas: uma delas se debruça sobre o desempenho dessas empresas iniciantes, destacando aquelas de alto crescimento; outra em suas características iniciais, sem relação direta com sua performance no mercado. 7 Utilizamos aqui uma ideia de startup que se assemelha mais a esse segundo tipo:empresas iniciantes - nascentes e novas-, caracterizadas por intensiva inovação, seja em modelo de negócios ou de base tecnológica, que se encontram em uma etapa temporária e passageira na qual busca recursos para identificare amadurecer seu negócio. ${ }^{8}$

A questão que nos move neste artigo é que, dada a sua importância no novo contexto de inovação, cada vez mais as startups são alvo tanto de políticas públicas para apoiar seu desenvolvimento como de ações privadas de grandes empresas buscando articulação para dinamizar processos de inovação. 
Governos nacionais e regionais buscam formas de se posicionar competitivamente para não só apoiar o movimento das startups em seus próprios territórios como também serem polos competitivos de atração de melhores projetos e de todos os demais atores que os circundam, tais como investidores e recursos humanos qualificados. O objetivo final é inovar, alimentar seus sistemas produtivos e gerar valor e empregos em seus territórios.

Grandes corporações têm dedicado esforços para estruturar mecanismos de aproximação que possam atingir diferentes momentos do desenvolvimento de uma startup para que, assim, sejam integrados elementos formadores de novas competências e capturados recursos que possam ser relevantes para a organização. 9

O presente artigo trata da importância das empresas iniciantes nesse novo contexto da inovação explorando essas duas frentes: uma é a presença cada vez maior de ações públicas de apoio ao empreendedorismo inovador, tanto internacionais como nacionais; outra é a disseminação da articulação entre grandes empresas e startups, fenômeno que ocorre em diferentes países e que ganhou força no Brasil nos últimos dez anos.

A compreensão do fenômeno se faz essencial também para que se construam bases para um olhar crítico tanto das ações privadas como, principalmente, das ações públicas. É comum escutar no debate público a assunção do empreendedorismo como panaceia para o crescimento econômico ou das startups como a solução para o desenvolvimento de sistemas produtivos mais inovadores. As tentativas ingênuas de imitar a experiência do Vale do Silício sem considerar as diferenças institucionais, culturais e econômicas locais ou mesmo as tentativas de transpor modelos como o das aceleradoras de empresas, do qual trataremos mais adiante, são um problema no debate público sobre o tema. Produzir informação nova e contribuir com essa reflexão mais crítica também é objetivo deste artigo.

Nesse sentido, o texto está estruturado da seguinte forma: na segunda parte, abordamos as políticas públicas para startups e inovação no cenário internacional e nacional; na terceira, apresentamos uma análise de ações privadas parastartups e inovação no Brasil, tendo como base um levantamento de programas de grandes empresas para articulação com startups; por fim, nas conclusões, discutimos desafios para lidar com a questão do empreendedorismo inovador.

\section{POLÍTICAS PÚBLICAS PARA INOVAÇÃO E STARTUPS}

As mudanças no contexto da inovação no século XXI, assim como as novas formas de atuação de diferentes atores, como as startups, se refletem nas políticas públicas. As formas de estímulo à inovação também se diversificam e se tornam mais complexas.
[9] VerTeece, Pisano e Shuen (1997) e Lubik, Ford e Despeisse (2016). 
[10] OECD, 2015; Torres-Freire; Maruyama; Polli, 2017.

[11] A terceira dimensão evidentemente é importante, mas não está diretamente relacionada ao argumento principal do artigo e por sua complexidade mereceria um trabalho à parte.

Além dos instrumentos tradicionais, como o crédito e o apoio financeiro não reembolsável, outros modos de suporte foram adaptados ou criados, especialmente para dar conta do apoio à inovação em startups. É sabido, por exemplo, que instrumentos tradicionais como o crédito não são adequados para empresas iniciantes, uma vez que, por seu curto histórico de vida, muitas ainda não têm faturamento nem ativos tangíveis que sirvam de garantias para concretizar a operação. Por outro lado, a criação de ambientes de interação, aprendizado e difusão de conhecimento, combinados ao desenvolvimento sistemático de um empreendimento, surgem como alternativas de apoio às startups.

De forma geral, é possível organizar o apoio à inovação em startups em três dimensões. A primeira se refere a investimento e capitalização: recursos públicos não reembolsáveis (subvenção econômica); os fundos de capital semente e de venture capital; fundos públicos e de coinvestimento público-privado; crowdfunding; e investimento direto corporativo em participação (corporate ventures). A segunda dimensão se refere a treinamentos, serviços de apoio e fomento ao ambiente empreendedor: os espaços para estímulo a inovação e desenvolvimento tecnológico, como incubadoras e aceleradoras; redes de empreendedores, investidores e clientes; eventos, cursos e workshops; além dos desafios tecnológicos públicos ou privados. Por fim, a terceira dimensão está relacionada ao marco regulatório, constituída pelo arcabouço normativo para investimento; regulação de incentivos fiscais a investidores em inovação e a empresas iniciantes; simplificação e modernização de processos administrativos para empresas inovadoras e iniciantes..$^{10}$

Neste artigo, trataremos das duas primeiras dimensões de apoio, capitalização das startups e ambiente empreendedor, ${ }^{11}$ buscando identificar exemplos internacionais e nacionais, tanto na esfera pública (nesta seção) como na privada (próxima seção), de modo a compor o argumento de que a nova dinâmica da inovação coloca em lugarcentral a participação das startups.

\section{CENÁRIO INTERNACIONAL}

As mudanças na dinâmica da inovação exigem constante evolução

[12] Há outras tendências interessantes ocorrendo pelo mundo. Um exemplo é o caso dos mecanismos de microfinanciamento coletivo baseados na internet, chamados de crowdfunding para startups, que podem ser: empréstimo, simples doação, troca do apoio financeiro por uma recompensa e a participação no capital social. EUA e França, por exemplo, já têm regulação específica. e diversificação dos mecanismos de fomento, com novos instrumentos e combinações dos existentes. A análise do contexto internacional atual para políticas públicas de apoio à inovação e a startups permite observar duas tendências principais: a presença do Estado como agente de compartilhamento de risco e como demandante de soluções inovadoras; $e$ as ações públicas para estimular a articulação de atores do ecossistema de inovação. ${ }^{12}$ 
O Estado como agente compartilhador de risco e demandante de tecnologia

No caso do compartilhamento de risco para o desenvolvimento tecnológico, a participação do Estado como agente indutor não é uma novidade. O papel do Estado em compartilhar o risco associado ao desenvolvimento tecnológico se consolidou nos países economicamente centrais durante o pós-guerra, como também se mostrou chave no modelo desenvolvimentista, cujo exemplo paradigmático é a Coreia do Sul. Mesmo no que se refere especificamente à formação da indústria de capital de risco, há exemplos de estímulo estatal. ${ }^{13}$ Entretanto, são dignas de nota iniciativas mais recentes que ilustram a disseminação de novas estratégias públicas direcionadas à inovação em startups.

Um exemplo de uso direto de recursos públicos não reembolsáveis é o Small Business Innovation Research (SBIR), de 1982, dos EUA, cujo objetivo é fortalecer a inovação nos projetos de pesquisa e desenvolvimento de pequenas empresas. Ministérios e agências anunciam suas demandas para que empresas nascentes respondam. As empresas recebem até US $\$ 150$ mil por seis meses para o estudo de viabilidade técnico-econômica do projeto e, na fase 2 , até US $\$ 1$ milhão por dois anos para o restante das atividades de $\mathrm{P} \& \mathrm{D}$. O programa é da década de 1980, mas o que mais chama a atenção é o fato de que o SBIR saltou de quinhentas empresas contempladas em 1983 para mais de 2,5 mil em 2012 , quando atingiu um volume financeiro de contratos de aproximadamente US $\$ 2$ bilhões, mostrando assim o aumento do apoio às empresas iniciantes inovadoras. ${ }^{14}$

Outro exemplo interessanteé que, desde 2005, ao menos doze países implementaram fundos de capital semente público-privados com o objetivo de alavancar recursos privados e, ao mesmo tempo, aproveitar a experiência dos atores do setor no auxílio ao desenvolvimento de startups. ${ }^{15} \mathrm{~A}$ ideia aqui é alocar o recurso público para uma política de inovação, dar mais segurança ao investidor privado e assim atraí-lo para o compartilhamento de risco e paralelamente garantir que o empreendimento terá um acompanhamento próximo e capacitado, aumentando assim a chance de sucesso da política. $\mathrm{Na}$ China, por exemplo, houve um crescimento significativo de fundos para startups apoiados pelo Estado: já são 780 , que receberam injeção de US\$ 231 bilhões em $2015 .^{16}$

Por fim, mesmo a Coreia do Sul, paradigma das políticas industriais com foco no desenvolvimento dos grandes grupos empresariais (chaebols), apresentou em suas diretrizes recentes o objetivo de priorizar as empresas nascentes, buscando tecnologias, conteúdos e modelos de negócio disruptivos. ${ }^{17}$

Quanto ao uso do poder de compra público para estimular a inovação, ele é historicamente associado ao esforço de P\&D nos setores de defesa pelo governo dos EUA e foi praticado extensivamente ao lon-

\begin{abstract}
[13] Alguns exemplos: o Industrial and Commercial Finance Corporation (ICFC), fundo descentralizado no Reino Unido para ajudar a revitalizar a economia britânica no pós-guerra; o Small Business Investment Companies (SBIC), programa lançado em 1958 pelos EUA, responsável pela maior parte dos investimentos em capital de risco no país mediante agentes licenciados pelo governo para realização dos aportes; e o Yozma Venture Capital, montado pelo governo israelense em 1992 com o objetivo de atrair capital e competências de investidores externos (Lerner, 2009; Plagge, 2006; Poncet, 2013).
\end{abstract}

[14] Tredgett; Coad, 2015.

[15] European Comission, 2016; OECD, 2014;2016.

[16] Oster; Chen, 2016.

[17] Coreia do Sul, 2013 . 
[18] Elder; Georghiou, 2007; Mowery, 2012; Sampat, 2012.

[19] OECD, 2011; 2012; 2014; Elder, 2013.

[20] Innovate UK, 2015; Tredgett; Coad, 2015.

[21] Os autores mencionam a importância maior dessa prática para as chamadas empresas de alto crescimento, que já passaram das fases iniciais do empreendimento (Mason; Brown, 2013).

[22] Y Combinator, 2016 go do século XX. ${ }^{18}$ Contudo, percebe-se uma mudança no uso desse mecanismo, seja pela sua disseminação internacional, seja pela sua orientação para empresas nascentes. Os desafios de inovação e encomendas tecnológicas ganham espaço em países como Alemanha, China e Reino Unido, que têm buscado formas mais diretas de articular os investimentos públicos em inovação a soluções para problemas específicos, além de promover a difusão de novas tecnologias. ${ }^{19}$

O Reino Unido, por exemplo, criou o programa Small Business Research Initiative (SBRI) em 2001 e logo depois a agência Innovate UK, que faz a mediação das necessidades do setor público com as pequenas empresas e organiza os desafios de inovação para objetivos específicos de interesse do governo britânico. Entre 2009 e 2013 , foram iniciadas pelo SBRI 173 competições e contratados $£ 166$ milhões em projetos, bens e serviços. ${ }^{20}$

Políticas públicas para articular atores envolvidos em inovação e empreendedorismo

A percepção da importância da articulação de diferentes atores para o processo de inovação é a base para diferentes ações públicas. Mason e Brown, por exemplo, defendem um movimento "das políticas financeiras para as políticas relacionais". Ou seja, a aproximação entre empreendedores e investidores pode ser tão ou mais importante do que oferecer recursos financeiros diretamente. ${ }^{21}$ Essa ideia se apoia na tese da constituição de atributos relacionais para o desenvolvimento de atividades baseadas em conhecimento e, assim, abre espaço para iniciativas de indução do Estado na promoção de estímulos para aproximar empreendedores, investidores, pesquisadores, clientes e fornecedores envolvidos no ecossistema de inovação.

O modelo de aceleração de empresas criado em 2005 pela Y Combinator no setor privado dos EUA estimulou uma série de iniciativas públicas nessa direção de pouco investimento, muito relacionamento e muitas atividades de capacitação. Em 2016, a aceleradora Y Combinator oferecia US $\$ 120$ mil para o empreendedor selecionado por $7 \%$ de participação na empresa para permanecer três meses no Vale do Silício, entre treinamentos, desenvolvimento do negócio e busca de investimento. O modelo contribuiu para a criação de 1,2 mil startups; sendo que, em 2015, dez de suas empresas egressas tinham valoração superior a US $\$ 500$ milhões, ${ }^{22}$ como Airbnb e Dropbox.

Houve uma disseminação de iniciativas privadas e também públicas de aceleração de empresas em países como Reino Unido, França, Irlanda, Chile e Brasil, apoiando-se no financiamento público ou na combinação deste com recursos privados, como: Climate-KIC, Le Camping, Oxygen Accelerator, NDRC LaunchPad, Seedcamp (I e II) eStart-Up Chile. 
Um problema é que, muitas vezes, as aceleradoras são implantadas sem considerar o fato de que as condições culturais e institucionais específicas do Vale do Silício, centrais para o sucesso na Califórnia, não se encontram em outras localidades. ${ }^{23}$ Ainda não houve tempo para avaliações dessas políticas, mas sabe-se que, no Brasil, as aceleradoras já começam a enfrentar problemas para se manter abertas por conta da dificuldade de geração de receita — em geral, ganham com a venda de sua participação em empresas de sucesso, mas isso demora para ocorrer ou não ocorre, dado o alto risco dos empreendimentos.

Para além dos programas de aceleração propriamente, os países buscam também diversificar suas iniciativas de apoio a inovação estartups.

Em 2012, o Reino Unido lançou um programa de apoio a um distrito tecnológico ao leste de Londres, conhecido como Tech City ou Roundabout do Silício, alusão ao Vale, na Califórnia. Essa iniciativa tinha como objetivo criar condições favoráveis para surgimento e crescimento de empresas de tecnologia da informação como também acelerar o debate e a formação de políticas públicas nesta direção. A partir daí um conjunto de iniciativas foi sendo criado. Tais projetos envolvem apoio financeiro a empresas de alto crescimento (Future Fifty), mentoria e qualificação para startups em estágio inicial (Upscale) e atração de empresas e empreendedores estrangeiros, até mesmo com um programa de emissão de vistos especiais para profissionais em tecnologias digitais (Tech Nation Visa). ${ }^{24}$

Portugal é outro país que tem implementado políticas voltadas a inovação e startups. O Startup Portugal, estratégia do governo português para empreendedorismo tecnológico, foi estruturado para execução em quatro anos com objetivos de estimular o ambiente local, investimentos e internacionalização. ${ }^{25}$ No estímulo ao ambiente, um eixo é a implantação de uma rede nacional de incubadoras, espaços makers e fab labs e zonas especiais de incentivos para desenvolvimento de tecnologia. Em Lisboa, por exemplo, há o Startup Lisboa, uma incubadora pública para negócios digitais responsável por abrigar algumas das principais empresas de TI portuguesas, como Uniplaces e Prodsmart. No eixo financiamento, o programa busca um conjunto de alternativas para o instrumento do crédito, inadequado para startups, promovendo o uso de crowdfunding, vouchers de inovação e coinvestimento público- privado. Por fim, no pilar de internacionalização, assim como o Reino Unido, Portugal busca se tornar um destino para atores estrangeiros. $\mathrm{O}$ país apresentou um crescimento mais rápido do que a média europeia, com mais de $€ 130$ milhões aportados de 2014 a 2016, ${ }^{26}$ algo notável se considerado que são iniciativas recentes e que se trata de um mercado interno relativamente pequeno no contexto europeu.

$\mathrm{Na}$ América Latina também se tem dado atenção a políticas de apoio às startups. Entre 2012 e 2015 , diversos instrumentos de po-
[23] Em estudo sobre o desenvolvimento da indústria de tecnologia da informação em duas regiões dos EUA, o próprio Vale do Silício, na Califórnia, e a Rota 128, em Massachusetts, Saxenian mostra a importância do contexto institucional e social no qual as empresas estão imersas e que moldam suas estratégias e estruturas (Saxenian, 1994, p. 7). Ver também: Marceau (2005) eSchrank (2017).

\footnotetext{
[24] Profissionais como engenheiros e cientistas de dados, engenheiros de hardware e desenvolvedores de software podem ser favorecidos com essa iniciativa.
}

[25] Startup Portugal, 2016.

[26] Startup Europe Partnership, 2017. 
[27] OECD, 2013; 2015 .

[28] Zacharakis; Shepard; Coombs, 2003; Isenberg, 2011; Kantis; Federico; Menéndez, 2012.

[29] O valor total investido é uma estimativa a partir de levantamento em documentos oficiais dos órgãos responsáveis pelos respectivos programas. Vale lembrar também que são os principais programas no país. Há outras iniciativas, de menor escala ou pontuais, que não foram listadas. líticas de apoio para esse segmento foram introduzidos em países como Chile, Colômbia, México, Peru, Uruguai e Panamá. ${ }^{27}$ No Brasil, nos últimos anos, também houve iniciativas dedicadas às startups, como veremos a seguir.

\section{POLÍTICAS PÚBLICAS PARA STARTUPS E INOVAÇ̃̃O: CENÁRIO NACIONAL}

Nos últimos quinze anos, de forma geral, o Brasil avançou em termos de políticas de inovação e do marco regulatório para o desenvolvimento tecnológico. Desde a criação dos Fundos Setoriais, ainda em 1999, passando pelo retorno das políticas industriais com a Política Industrial, Tecnológica e de Comércio Exterior (PITCE) e a Lei de Inovação, em 2004, até a programas mais recentes, como o Inova Empresa, em 2013, houve uma diversificação do espectro de mecanismos de apoio à inovação.

No que se refere ao empreendedorismo inovador não foi diferente. Foram criados diferentes programas que diretamente ou indiretamente contribuem para o desenvolvimento de empresas iniciantes e pequenas que desejam inovar. Essas ações vêm tornando o ambiente para o empreendedorismo inovador no Brasil mais complexo e diversificado.

Assim como em outros países, os formuladores de políticas para inovação e startups precisam considerar em seu rol de preocupações não apenas a questão de investimento e capitalização de empresas como também um conjunto de atores e mecanismos de governança que compõem essas redes de organizações e instituições: empreendedores, investidores, pesquisadores em instituições de ciência e tecnologia, grandes empresas, além de associações, incubadoras, aceleradoras e mentores. ${ }^{28}$

De alguma forma, o Brasil avançou nesse objetivo, como se pode ver na lista de programas no Quadro 1. Nem todos os programas são diretamente voltados a startups e inovação, mas de uma forma ou outra acabam por estimular esse binômio. De 1998 até 2017 , levantamos 25 programas principais, de dezesseis instituições diferentes, sendo 21 deles ainda em vigência, três de instituições público-privadas. Em vinte anos, a estimativa total de investimento é próxima de $\mathrm{R} \$ 5$ bilhões. ${ }^{29}$

Apesar dos avanços, por outro lado, ainda há lacunas, sobreposições e problemas em relação ao apoio público para o empreendedorismo inovador no país. A seguir, discutimos alguns programas considerando as dimensões investimento e ambiente empreendedor, conforme estrutura apresentada anteriormente.

Apoio público para investimento e capitalização de startups no Brasil

Tendências vistas no cenário internacional também são observadas, ainda que em menor escala, nas iniciativas públicas brasileiras. 
QUADROI

Programas de apoio a pequenas empresas no Brasil

\begin{tabular}{|c|c|c|c|}
\hline Nome do programa & Instituição & Vigência & Valor total (investido ou estimado) \\
\hline $\begin{array}{l}\text { Conexão } \\
\text { Startup-Indústria }\end{array}$ & ABDI & 2017-em vigência & R\$10 milhões \\
\hline Criatec I & BNDES & $2007-2011$ & $\begin{array}{l}\text { Patrimônio comprometido: } \\
\text { R\$100 milhões. Aportes: } \mathrm{R} \$ 68 \text { milhões }\end{array}$ \\
\hline Criatec II & BNDES & 2013-em vigência & $\begin{array}{l}\text { Patrimônio comprometido de } \mathrm{R} \$ 186 \text { milhões. } \\
\text { Aportes: } \mathrm{R} \$ 20 \text { milhões }\end{array}$ \\
\hline Criatec III & BNDES & 2016-em vigência & Patrimônio comprometido de $\mathrm{R} \$ 202,5$ milhões \\
\hline BNDES MPME Inovadora & BNDES & 2014-em vigência & 2014-2015: R 261,2 milhões. 2016-2018: $\mathrm{R} \$ 300$ milhões \\
\hline Inova Talentos & $\mathrm{CNI} / \mathrm{CNPq}$ & 2013-em vigência & $\begin{array}{l}\text { 2014: } \mathrm{R} \$ 24 \text { milhões. } 2015 \text { : } \mathrm{R} \$ 29 \text { milhões. 2016: } \\
\mathrm{R} \$ 6,4 \text { milhões (bolsas) }\end{array}$ \\
\hline Procompi & $\mathrm{CNI} /$ Sebrae & 1998-em vigência & 2010-2015: $\mathrm{R} \$ 30$ milhões. 2016-2019: $\mathrm{R} \$ 23,9$ milhões \\
\hline RHAE & $\mathrm{CNPq}$ & $1987-2016$ & 2007-2013, 4.272 bolsas, totalizando $\mathrm{R} \$ 236$ milhões \\
\hline Pipe I e II & Fapesp & 1997-em vigência & $\mathrm{R} \$ 360$ milhões (até 2016) \\
\hline Inovar & Finep & 2013-em vigência & Patrimônio total dos fundos: $\mathrm{R} \$ 577$ milhões (2015) \\
\hline $\begin{array}{l}\text { Pappe Subvenção/ } \\
\text { Integração }\end{array}$ & Finep & 2006-em vigência & $\mathrm{R} \$ 245$ milhões Finep e $\mathrm{R} \$ 95$ milhões dos estados \\
\hline Tecnova & Finep & 2012-em vigência & R\$190 milhões \\
\hline Inovacred & Finep & 2014-em vigência & 2014-2015: R \$ 747,5 milhões \\
\hline Pipe/Pappe(PIPE III) & Finep/Fapesp & 2005-em vigência & $\mathrm{R} \$ 21,1$ milhões (até 2015) \\
\hline Finep Startup & Finep & 2017-em vigência & $\mathrm{R} \$ 25$ milhões \\
\hline Seed-MG & Governo estado MG & 2013-em vigência & Estimado em $R \$ 23$ milhões \\
\hline Sinapse da Inovação & Governo estado SC & 2005-em vigência & $\mathrm{R} \$ 21,3$ milhões (até 2014) \\
\hline Pitch-GovSP & Governo estado SP & 2015-em vigência & Sem aporte financeiro (convênios) \\
\hline Startup Brasil & MCTI & $2012-2020$ & $\mathrm{R} \$ 80$ milhões \\
\hline PNI (Incubadoras) & $\mathrm{MCTI} / \mathrm{CNPq}$ & $2002-2012$ & R\$141 milhões \\
\hline Inovativa & MDIC & 2013-em vigência & R\$ 7 milhões (2013-2015) \\
\hline Techsampa (Vaitec) & Prefeitura SP & 2014-em vigência & $\mathrm{R} \$ 3$ milhões \\
\hline $\begin{array}{l}\text { ALI (Agentes Locais de } \\
\text { Inovação) }\end{array}$ & Sebrae & 2008-em vigência & $\begin{array}{l}\text { 2010-2015: R\$202,7 milhões. 2015-2020: } \\
\mathrm{R} \$ 320 \text { milhões }\end{array}$ \\
\hline Sebraelab & Sebrae & 2016-em vigência & Sem informação \\
\hline Sesi-Senai de Inovação & Sesi/Senai & 2004-em vigência & Aproximadamente $\mathrm{R} \$ 380$ milhões \\
\hline
\end{tabular}

Desde 2000 , a Finep tem participado no fornecimento de recursos mediante fundos de capital de risco voltados para pequenas empresas inovadoras. O projeto Inovar, por exemplo, tem como principal objetivo o apoio financeiro, casos do Inovar Fundos, do Inovar Semente e do Inovar Anjos. Até 2014, foram aprovados pela Finep investimentos em oito fundos de capital semente, que aportaram recursos em 45 empresas inovadoras. O patrimônio total dos fundoséde $\mathrm{R} \$ 577$ milhões, sendo que os recursos comprometidos pela Finep são de R 292 milhões, o que significa uma alavancagem de 1,98 no mercado - ou seja, a cada R 1 da Finep em fundos de capital semente, outro R $\$$ I éinvestido por atores privados. $3^{\circ}$

[30] Finep, 2016 . 
Outra iniciativa importante para o desenvolvimento do setor de capital de risco no Brasil foi a instituição pelo BNDES do fundo de capital semente Criatec.Em 2007, o banco deu início ao primeiro fundo da série, cujo objetivo é obter ganho de capital por meio de investimento de longo prazo emempresas em estágio inicial com perfil inovador eque projetem um retorno elevado. O fundo Criatec 1 teve $\mathrm{R} \$ 100$ milhões de capital comprometido, dos quais foram usados $\mathrm{R} \$ 68$ milhões em aportes em 36 empresas. Em sua segunda chamada, foram reservados $\mathrm{R} \$ 186 \mathrm{mi}-$ lhões, dos quais 25 empresas receberam cerca de $\mathrm{R} \$ 20$ milhões. Por fim, o Criatec 3, iniciado em 2016, possui capital comprometido de $\mathrm{R} \$ 202$ milhões. Ou seja, com exceção deste último, recém-criado, o capital colocado à disposição nas fases 1 e 2 não foi totalmente utilizado.

Buscando preencher a lacuna entre o primeiro investimento na fase inicial do empreendimento (normalmente realizado por investidores-anjo) e os aportes realizados pelos fundos de investimento semente em uma etapa em que o empreendimento se encontra mais consolidado, em 2017 foi lançado o Finep Startup. Essa ação busca alavancar empresas de base tecnológica com alto potencial de crescimento que estejam em fase final de desenvolvimento do produto, para colocar no mercado ou para ganhar escala de produção. O primeiro edital coloca à disposição $\mathrm{R} \$ 50$ milhões, que serão distribuídos em 2017 e em 2018 para cinquenta empresas (25 por ano). As startups selecionadas poderão receber investimentos de até $\mathrm{R} \$ 1$ milhão, por meio de contrato de opção de compra de participação na empresa, uma novidade em termos de instrumento público de fomento.

Já em âmbito regional, a Pesquisa Inovativa em Pequenas Empresas (Pipe), da Fapesp, é considerada um dos maiores programas de suporte ao empreendedorismo inovador no país, oferecendo apoio financeiro não retornável a projetos de empresas nascentes, dando apoio a empreendedores para transformar conhecimento em novos produtos ou serviços e fomentando a inovação em uma etapa crucial e de alto risco, que é o seu nascimento. O programa, inspirado no SBIR, dos EUA, foi uma novidade no Brasil em 1998 ao apoiar pequenas empresas com projetos de desenvolvimento tecnológico em parceria com universidades e institutos de pesquisa.

Em 2017, a Pipe completou vinte anos de existência com 1.788 projetos de pesquisa apoiados em 1.110 empresas de 127 municípios do estado de São Paulo, com um investimento total de R $\$ 360$ milhões ao

[31] Salles Filho, 2015.

[32] Marques, 2017. longo desse período. De acordo com Salles Filho, ${ }^{31}$ cada $\mathrm{R} \$ 1$ alocado pela Fapesp no programa geram $\mathrm{R} \$ 10,50$ de retorno, além do aumento na contratação de profissionais qualificados. ${ }^{32}$

Os Programas de Apoio à Pesquisa em Empresas (Pappe), em que se associam o Ministério de Ciência, Tecnologia e Inovação (MCTI), a Finep e as fundações de amparo à pesquisa, vieram a complementar 
iniciativas como o Pipe, levando maior aporte de recursos às empresas em fases mais avançadas do desenvolvimento tecnológico. Por exemplo, o Pipe apoia as fases 1 e 2, de R\$200 mil a R\$ 1 milhão, por volta de três anos, e a Finep apoia a fase 3 do projeto, com novo aporte de recursos para continuação do empreendimento.

Também em âmbito regional, o programa Sinapse da Inovação é uma ação promovida pelo Governo de Santa Catarina em conjunto com a Fundação de Apoio à Pesquisa Científica e Tecnológica do Estado de Santa Catarina (Fapesc) e o Sebrae SC e executado pela Fundação Centros de Referência em Tecnologias Inovadoras (Certi). O programa busca aproximar pesquisa científica e tecnológica, praticada principalmente nas universidades e ICTs, da geração de produtos impulsionadores de novas empresas. Desde 2008, o programa gerou 294 empresas, das quais 245 ( $83 \%$ do total) ainda se mantêm ativas, gerando faturamento estimado de $\mathrm{R} \$ 120$ milhões. 33 Devido aos bons resultados, o modelo foi adotado por outros estados, como Amazonas e Espírito Santo.

\section{Apoio público para o ambiente de empreendedorismo inovador no Brasil}

Um programa que uniu o objetivo de capitalizar as empresas nascentes com o estímulo ao ambiente inovador e a articulação de atores do ecossistema foi o Startup Brasil. Criado em 2012, é uma iniciativa do MCTI, com gestão da Softex e em parceria com aceleradoras, para apoiar empresas nascentes de base tecnológica. As empresas selecionadas recebem $\mathrm{R} \$ 200$ mil para cobrir custos com recursos humanos e são abrigadas em aceleradoras, onde recebem treinamento, mentoria e apoio ao desenvolvimento do negócio, além de estarem em contato com empresas parceiras e investidores. O programa é interessante ao apoiar ao mesmo tempo tanto as startups como as aceleradoras, pois capitaliza as empresas e aumenta sua chance de sucesso, o que beneficiaria as aceleradoras, que dependem da venda de participação das empresas investidas para geração de receitas. O ponto negativo é que os recursos só podem ser utilizados para pagamento de recursos humanos, uma vez que a fonteé o CNPq.

Outros dois programas no Brasil nos últimos anos se destacam pelo foco na articulação e integração de atores, ou seja, na ideia de "políticas relacionais".

O primeiro é o InovAtiva, um programa de capacitação, mentoria e conexão para empresas iniciantes e inovadoras no Brasil de qualquer setor. É realizado pelo Ministério da Indústria, Comércio Exterior e Serviços (MDIC), em parceria com o Serviço Brasileiro de Apoio às Micro e Pequenas Empresas (Sebrae), e tem execução da Fundação Certi. A ideia do InovAtiva surge da constatação de que a maior parte dos potenciais empreendedores tinha pouco ou nenhum conhecimento em negócios, carecendo de capacidade
[33] "Resultados do Sinapse" em SC, 2016. 
[34] InovAtiva Brasil, 2016.

[35] Mais informações em: https:// startupindustria.com.br.

[36] Decreto Municipal no $55.461 /$ 2014. de transformar a ideia em produto ou em solução para o mercado. O diagnóstico é que, além da falta de capacitação, os empreendedores de alta tecnologia tinham pouco contato com atores do mercado, como empresários, investidores e outros empreendedores. O InovAtiva foi criado justamente com essa preocupação de preparar os empreendimentos inovadores iniciantes para receberem investimento. ${ }^{34}$

O segundo é o Programa Nacional Conexão Startup-Indústria, uma iniciativa recente da Agência Brasileira de Desenvolvimento Industrial (ABDI) para promover a articulação entre startups e empresas do setor industrial, com foco em ações de integração digital das diferentes etapas da cadeia de valor dos produtos industriais. 35 A iniciativa tem investimentos de $\mathrm{R} \$ 10$ milhões no primeiro ano, mas com possibilidades de mais de $\mathrm{R} \$ 50$ milhões nos próximos três anos. De novo, o foco aqui não é a capitalização das startups por meio de um programa público, mas sim aproximá-las de grandes empresas interessadas em desenvolver tecnologia em parceria.

Para além dessas iniciativas de alcance nacional, outras ações estaduais e municipais de apoio às startups têm sido implantadas, seja mediante concessão de recursos financeiros, seja para acesso a redes ou constituindo planos estratégicos nessa área.

Em São Paulo, foi criado um conjunto de iniciativas favoráveis ao desenvolvimento do empreendedorismo inovador a partir do TechSampa, política municipal de estímulo à inovação e ao desenvolvimento de startups na cidade em $2014 .{ }^{6}$ Dentre suas iniciativas de maior reverberação está o SP Stars, programa de mentores voluntários parastartups. Em suas duas edições já foram beneficiadas cerca de cem startups e se formou uma rede de cerca de trezentos mentores qualificados, composta por fundadores de startups, aceleradoras, grandes empresas, investidores e agentes locais. Já o programa Empreenda Fácil, iniciativa da Prefeitura de São Paulo em parceria com os governos do estado e federal, tem o objetivo de reduzir para uma semana o prazo de abertura e licenciamento de empresas, que antes poderia levar mais de cem dias. Por fim, o Mobilab e o Pátio Digital, iniciativas da Secretaria Municipal de Transporte e da Secretaria Municipal de Educação de São Paulo, respectivamente, despontam como interessantes laboratórios setoriais de diálogo entre as startups e a administração pública na busca por soluções mais ágeis para o governo ou como plataforma para inovação sem necessariamente $o$ aporte de recursos financeiros.

Em Minas Gerais, o Startups and Entrepreneurship Ecosystem Development (Seed) é um programa de aceleração de startups para empreendedores de qualquer país que queiram desenvolver seus negócios no estado. Baseado no modelo do Start-Up Chile e coordenado pela Secretaria de Desenvolvimento Econômico, Ciência, Tecnologia 
e Ensino Superior (Sedectes), o Seed é parte do Minas Digital, uma série de iniciativas públicas, parcerias e formação de rede que busca impulsionar o desenvolvimento de negócios inovadores e fortalecer a cultura empreendedora no estado. Por rodada, são selecionadas quarenta startups, que recebem um capital semente de $\mathrm{R} \$ 68 \mathrm{mil}$ a $\mathrm{R} \$ 80$ mil, em um programa com duração de cerca de seis meses. Ao todo já foram apoiadas 198 startups, das quais 36 de outros países.

A multiplicação de iniciativas de apoio às startups indica uma evolução no ambiente de empreendedorismo inovador brasileiro nos últimos quinze anos. Essa diversidade não só contempla diferentes dimensões de apoio ao desenvolvimento empreendedor iniciante inovador como também, em menor escala, quase todas as categorias de apoio oferecidas em outras partes do mundo.

Apesar dessa amplitude de iniciativas, o conjunto de ações públicas oferecido no Brasil ainda demanda aperfeiçoamento em termos de prioridade, escala, estabilidade e eficiência. Um gargalo é o fornecimento de recursos financeiros para utilização pela startup sem limitação de rubricas (recursos humanos, marketing e canais de mercado, desenvolvimento de protótipo etc.), como investimento direto conversível em participação ou subvenção econômica. 37 Também é necessário incorporar o monitoramento constante das empresas apoiadas e processos sistemáticos de avaliação de seus investimentos, ações e resultados.

No mesmo caminho de diversificação do ambiente doempreendedorismo inovador que vimos no âmbito das políticas públicas, nos últimos anos, vem ganhando força no Brasil um fenômeno mundial em que grandes empresas buscam se aproximar das startups motivadas por conquistar novos mercados, identificar novas rotas tecnológicas ou oxigenar as culturas organizacionais. Vejamos tal fenômeno na próxima seção.

\section{AÇÕES PRIVADAS PARA STARTUPS E INOVAÇÃO NO BRASIL}

A articulação entre grandes empresas e startups com o objetivo de desenvolver inovação vem se disseminando em diferentes países nos últimos anos, principalmente pelo interesse das primeiras em se conectar ao desenvolvimento tecnológico e a novos modelos de negócios que surgem no ambiente empreendedor. Os motivos mais específicos para a busca dessa colaboração com startups passam por: acesso a novos mercados, redes de conhecimento e recursos humanos especializados; solução de problemas específicos, como teste de produtos e de escala das operações; e estímulo à cultura de inovação interna da empresa. ${ }^{38}$

O fenômeno de uma grande empresa buscar parcerias para inovação com empresas pequenas não é em si novo. Mas a dimensão
[37] Uma questão crítica apontada de forma recorrente em debates públicos e na literatura sobre o tema diz respeito às barreiras regulatórias para empreender no Brasil (Endeavor, 2015; World Bank, 2016). Mesmo sendo insuficientes frente ao escopo desses problemas, houve avanços nos últimos anos no Brasil: normatização da sociedade anônima simplificada (PLC n ${ }^{\circ} 4.303 / 2012$ ); regulamentação da figura do investidor anjo (PLC $\mathrm{n}^{\circ}$ 25/2007); Novo Marco Legal da Inovação (Lei no 13.243/2016), que, entre outros pontos, facilita a criação de empresas a partir de resultados da pesquisa em instituições de ciência e tecnologia (ICTs); regulação da oferta pública de distribuição de valores de emissão de sociedades empresárias de pequeno porte, realizada com dispensa de registro por meio de plataforma eletrônica de investimento participativo (ICVM $\left.\mathrm{n}^{\circ} 588 / 17\right)$, o crowdfunding.

[38] Dee et al., 2015; Kohler, 2016; Mocker; Bielli; Haley, 2015; World Economic Forum, 2015. 
[39] Não entraremos aqui no debate sobre o conceito de corporate venturing. Neste artigo, nos limitamos à discussão do fenômeno de articulação de grandes empresas com startups. Na literatura da área de administração, o corporate venturing é entendido como um esforço corporativo para criação de novos negócios, internos ou externos, para explorar novos mercados, obter novos produtos ou até mesmo gerar novas unidades de negócios (Rieche; Faria, 2014; Mocker; Bielli; Hale, 2015; Kohler, 2016).

[40] Ver HBS Alumni Angels of Brazil (2017).

[41] Foram consultados: associações de classe, como Associação Brasileira de Startups (ABStartups), Associação Nacional de Entidades Promotoras de Empreendimentos Inovadores (Anprotec), Associação Brasileira de Aceleradoras de Inovação e Investimento, Anjos do Brasil, Associação Brasileira de Private Equity e Venture Capital (ABVCAP); portais especializados no tema, como Startupi e Startse; organizações públicas e entidades nacionais envolvidas no tema, como Fundação Getúlio Vargas (FGV), Sebrae, Associação Nacional de Pesquisa e Desenvolvimento das Empresas Inovadoras (Anpei), Endeavor e que tomou nos últimos anos parece ser novidade, assim como o interesse dos formuladores de política por esse tipo de articulação. Os exemplos citados anteriormente ilustram como programas públicos de fomento à inovação buscam a participação do setor privado, como investidores e mentores em processos de desenvolvimento de startups, conforme apresentado, ou como empresas consolidadas no mercado para se articular a startups para desenvolver inovações, conforme exploramos ao longo desta seção.

As grandes empresas estão criando mecanismos para fazer essa articulação com startups no mundo todo. Os exemplos são inúmeros, como o Jlabs da Johnson \& Johnson, o GE Ventures, o Novartis Venture Funds, o SmartCamp da IBM e o Siemens Venture Capital, entre muitos outros. E o interesse corporativo em startups é crescente, como se vê, por exemplo, na Europa: um terço (31 de 103) das aceleradoras europeias é apoiado ou mantido por grandes empresas; em 2014 , os investimentos globais de fundos de investimento corporativos cresceram $86,5 \%$ em valor e $59 \%$ em número, totalizando 1.734 negócios, que somaram US $\$ 48,5$ bilhões, e saídas no valor de US $\$ 84,2$ bilhões. 39

No Brasil, a articulação entre grande empresa e startup também cresceu nos anos recentes, acompanhando, em menor escala, o que ocorre no contexto internacional, como os programas de aceleração ou incubação (InovaBra, do Bradesco; Oxigênio, da Porto Seguro), espaços de inovação e coworking (Cubo, do Itaú; Google Campus; Samsung Ocean), além de prêmios e eventos (como Desafio Pfizer e Circuito Einstein de Startups).

Mas o que há realmente no Brasil nesse campo? O que está sendo feito e de que forma? De fato, há pouca informação sistematizada sobre as ações privadas em direção a startups no país..$^{\circ}$ Nesse sentido, dois passos são necessários para compreender o cenário nacional: uma coleta sistemática de informação e uma estrutura de análise para organizar os tipos de ação.

\section{LEVANTAMENTO DE INFORMAÇÕES E ESTRUTURA DE ANÁLISE DOS TIPOS DE APOIO A STARTUPS}

A pesquisa exploratória aqui apresentada foi realizada sistematicamente entre março de 2016 e junho de 2017 em diversos canais de informação em páginas on-line especializadas no tema e das próprias empresas para identificação das ações..$^{1} \mathrm{O}$ universo de análise são os diferentes mecanismos e instrumentos de apoio de grandes empresas estartups. Como se trata de um fenômeno recente e dinâmico, com frequente lançamento de iniciativas, ainda não existe no Brasil um banco de dados com essas informações consolidadas. 
Por isso, fizemos um levantamento dessas informações em três etapas:

1. Varredura horizontal para identificar empresas com algum tipo de ação direcionada exclusivamente para startups, sendo dividida em duas fases: busca on-line por palavras-chaves e averiguação de páginas web de ações públicas e privadas para fomento e desenvolvimento do empreendedorismo.

2.Varredura vertical sobre cada uma dessas empresas para a compreensão do nível de relacionamento dessas organizações.

3. Exploração sistemática das fontes citadas para alimentação do banco de dados.

Com isso, foi possível traçar um panorama das iniciativas corporativas de relacionamento com as startups, enquadrando-as em tipos de apoio e os objetivos almejados com a ação. De antemão, ressalta-se que qualquer modelo de taxonomia simplifica o fenômeno, mas, ao mesmo tempo, permite analisá-lo sistematicamente.

Os fatores considerados para classificar os tipos de iniciativas entre corporações e startups foram: infraestrutura e espaço de interação (interno ou externo à empresa âncora); o grau de dependência da empresa âncora (dependência plena até nenhuma relação); a extensão da inovação (oscila entre imitação e disrupção); e a natureza do apoio (autonomia e dependência formal nas decisões do negócio).

No país, encontramos 175 empresas, das quais 63 nacionais, com 217 ações direcionadas a startups. A partir dos parâmetros acima, buscamos organizar essas ações nos seguintes tipos: 1. eventos independentes, como desafios e concursos para startups; 2 . compartilhamento de recursos, como espaços de coworking, acesso a serviços e ferramentas corporativas e capacitação; e 3. apoio para desenvolvimento de novos negócios e iniciativas de investimento de risco..$^{2}$

Salientamos que a parceria entre grandes empresas estartups pode acontecer de diferentes modos-desde um contrato de curto prazo para o fornecimento de uma solução específica até uma parceria de longa duração para codesenvolvimento de novas tecnologias. Dada a complexidade dessa articulação, as ações das empresas podem, por vezes, permear mais de um objetivo estratégico e se encaixar em mais de um tipo aqui apresentado. Ou seja, em alguns casos, existe uma sobreposição de atividades, o que dificulta uma classificação precisa das categorias. Além disso, como o fenômeno está em constante evolução, os tipos podem não contemplar toda a diversidade de ações.

Independentemente dessas ponderações, o levantamento mostra um número expressivo de ações de empresas de diferentes setores, como financeiro, tecnologia da informação, saúde, química, telecomunicações e construção civil. Nesse sentido, o interessante é apresentar alguns desses casos organizados nessas categorias, de modo a contribuir para o entendimento do fenômeno da articulação entre grandes empresas estartups no Brasil.
Agência USP de Inovação.

\footnotetext{
[42] Na literatura internacional, pelo menos dois outros tipos aparecem com destaque: as parcerias para desenvolvimento conjunto de produtos e serviços e os investimentos e aquisições. Optamos por não tratar os dois tipos separadamente dos outros neste artigo. No primeiro caso, entendemos que as parcerias ainda estão bastante relacionadas a ações de compartilhamento de recursos e de programas de aceleração. No segundo caso, argumentamos que a ação de aquisição ou investimento direto da empresa na startup se aproxima mais da compra de ativos, algo mais conhecido e já discutido na literatura (World Economic Forum, 2015; Mocker; Bielli; Haley, 2015; Dee et al., 2015; Kohler, 2016).
} 
[43] Mocker; Bielli; Haley, 2015.

[44] Mais informações em: http:// www.openstartups.org.br.
[45] Mais informações em: https:// www.einstein.br/estrutura/inovacao/ inova-einstein-circuito-startups.

[46] Mais informações em: https:// desafiopfizer.com.br.

[47] Mais informações em: http:// www.edp.com.br/edp-comerciali zacao/noticias/Paginas/2016/06/ EDP-lan $\% \mathrm{C}_{3} \% \mathrm{~A}_{7} \mathrm{a}-\mathrm{EDP}-\mathrm{Open}-$ Inovation.aspx.

\section{DESAFIOS, CONCURSOS E EVENTOS PARA STARTUPS}

Ações pontuais, normalmente no formato de competições, tais como desafios, concursos e os chamados hackathons, são ações de corporações que buscam iniciar um contato com as startups para gerar mudanças culturais internas, fornecer novas perspectivas de mercado e de tecnologias, assim como associar a marca da empresa com uma ideia de inovação. 43

No Brasil, o movimento "10o Open Startups"44 é uma referência de ação voltada para aproximar corporações e empresas nascentes. É uma iniciativa independente que se materializa em uma plataforma digital e na realização de eventos presenciais. Na plataforma, os temas de interesse das grandes empresas são organizados em desafios - tais como "indústria do futuro" ou "wearables"-, e as startups se inscrevem nos desafios para os quais desejam oferecer soluções. Outros atores do ecossistema, como mentores, especialistas técnicos e investidores, também são convidados a ingressar na plataforma para avaliar e dar sugestões às empresas nascentes. A partir das avaliações recebidas e dos negócios fechados, as startups inscritas são continuamente ranqueadas e selecionadas para eventos como o "Open Innovation Week" e "Demodays". Até 2016, foram formalizados 53 contratos entre as startups classificadas e as 82 empresas conectadas.

Com essa mesma perspectiva, mas com uma abordagem exclusiva para o setor de saúde, o Circuito Einstein de Startups é uma das iniciativas da estratégia de inovação do Hospital Israelita Albert Einstein. É voltado para empresas com atécem funcionários e faturamento anual que não ultrapasse $\mathrm{R} \$ 10$ milhões e que atuem na área da saúde. As startups selecionadas apresentam novos produtos em um evento com profissionais do Einstein e possíveis investidores. ${ }^{45}$

Outro exemplo na área é o Desafio Pfizer, concurso para startups criado pela farmacêutica que seleciona startups e inventores com inovações para a indústria de saúde. Os primeiros colocados recebem mentoria de três meses com executivos nacionais e internacionais da Pfizer. ${ }^{6} 6$

A EDP Brasil, empresa da área de energia, lançou em 2016 o EDP Open Innovation, ${ }^{47}$ prêmio global destinado a startups do setor com o objetivo de identificar negócios inovadores. A iniciativa nasce de uma parceria de empresas portuguesas - jornal Expresso e aceleradora Fábrica de Startups-, e os selecionados realizam o programa de aceleração em Lisboa, participam do "Web Summit", maior evento destartups de tecnologia da Europa, e concorrem a $€ 50$ mil para o desenvolvimento da ideia.

Grandes empresas que outrora foram startups e se tornaram referências em determinados setores começam também a investir. $\mathrm{O}$ 
Buscapé, maior plataforma de comparação de preço da América Latina, fundado em 1998 e adquirido pelo conglomerado de mídia sul-africano Naspers Limited, ${ }^{48}$ criou em 2011 o concurso "Sua ideia vale 1 milhão", iniciativa que apoia projetos com $\mathrm{R} \$ 300$ mil mediante parcela de $30 \%$ na empresa. Já a Locaweb, de serviços para internet, criada em 1997, desenvolveu seu programa de aceleração chamado Locaweb Startup 49 em parceria com a Endeavor..$^{\circ}$ Os vencedores ganham $\mathrm{R} \$ 30$ mil, infraestrutura e mentoria.

Por fim, os hackathons ${ }^{51}$ são desafios com temas predefinidos e duração de 24 a 54 horas ininterruptas. Por ser uma atividade de pouco compromisso e mais simples de executar, esse tipo de programa virou moda entre as empresas e já foi promovido por inúmeras corporações, como Ambev, L'Oréal, Globo, IBM e Microsoft.

\section{COMPARTILHAMENTO DE RECURSOS, COMO ESPAÇOS DE COWORKING, ACESSO A SERVIÇOS E FERRAMENTAS CORPORATIVAS E A CAPACITAÇÃO}

A prática de compartilhar recursos com startups para estimular inovação é outra forma disseminada entre as grandes empresas, já que, além da inovação em si, potencializa a construção de uma rede de novos fornecedores especializados e de consumidores que poderão testar tecnologias em lançamento.

Dentre as ações mais comuns está o uso gratuito ou subsidiado de serviços, produtos e ferramentas ou acesso a conhecimentos. Um caso é o programa Google Developers Startup Launch, serviço do Google para startups, que fornece às empresas, em todas as fases de desenvolvimento, plataforma, conteúdo on-line, orientação e formação para o desenvolvimento de novos projetos.

Há também ações desse tipo em espaços de uso compartilhado e gratuito com o intuito de promover capacitação para novas tecnologias ou experimentação de projetos. Inaugurado em 2014 e presente em São Paulo e Manaus, o Samsung Ocean ${ }^{52}$ é uma iniciativa da gigante sul-coreana que oferece capacitação e treinamentos ligados a temas específicos, como desenvolvimento de aplicativos e internet das coisas. Em tais espaços, são cedidos recursos da própria corporação para que sejam realizados testes e validação de novos produtos. Busca-se, assim, montar uma rede de criadores de aplicativos para expandir as possibilidades de suas áreas de P\&D além de contar com novas soluções para seus sistemas.

Outro exemplo é o Garagem 11.57. Lançado em 2017, é um espaço concebido para apoiar projetos inovadores que usam a plataforma IBM Bluemix em áreas como computação cognitiva, internet das coisas e blockchain. Os parceiros e clientes têm o apoio de especialistas da IBM para seus projetos.
[48] Mais informações em: http:// www.buscapecompany.com/portal/ buscape-company/sobre-nos/ nossa-historia.

[49] Mais informações em: http:// programalocawebstartup.org.

[50] A Endeavor é uma organização sem fins lucrativos presente em mais devinte países de apoio a empreendedores de alto impacto. Mais informações em: https://endeavor.org.br

[51] Termo formado da junção das palavras "hack" e "marathon" criado por desenvolvedores de software da OpenBSD. O termo "hack", neste caso, é usado no senso de "exploração". Mais infomações em: https:// en.wikipedia.org/wiki/Hackathon.

[52] Mais informações em: http:// oceanbrasil.com. 
[53] Mais informações em: http:// www.natura.com.br/a-natura/ inovacao/startups.

[54] Mais informações em: http:// www.inovacaoaes.com. br/blog/2017/04/13/aes-brasildiscute-o-futuro-da-energia-eminauguracao-de-espaco-no-cubo.

[55] Mais informações em: http:// www.totvslabs.com.

[56] Mais informações em: http:// www.bb.com.br/pbb/pagina-inicial/ imprensa/n/53743/banco-dobrasil-instala-laboratorio-novale-do-silicio\#.

[57] Mais informações em: https:// cubo.network.

[58] Mais informações em: http:// rpev.com.br.

[59] Programa de parceria entre comunidades de startups para orientar empresários e incentivá-los a criar um ecossistema para o desenvolvimento de soluções e produtos inovadores no mercado. Mais informações em: https://www.googleforentrepre neurs.com/
Tais ações são em geral usadas para que as empresas tentem se antecipar a tendências em áreas estratégicas para seus negócios. $\mathrm{O} \mathrm{Na}$ tura Startups, 53 por exemplo, é uma iniciativa de aproximação com startups e negócios de base tecnológica com inovações em temas de interesse da empresa, como tecnologias verdes e novas formulações e ingredientes de cosméticos. Essa aproximação parte da premissa de que a colaboração por meio de redes de inovação é fundamental para a atualização da empresa.

O AES Brasil Inovação, programa da empresa de energia elétrica AES em parceria com a Liga Ventures, consultoria que dá suporte a empresas na formulação de programas para startups, busca projetos em áreas como eficiência energética e internet das coisas. Os selecionados podem receber até $\mathrm{R} \$ 500$ mil em aporte não reembolsável em troca de parceria intelectual e comercial do projeto desenvolvido em conjunto. 54

A conexão com ambientes globais de startups também é alvo de algumas empresas.A Totvs, maior empresa brasileira de software corporativo, iniciou em 2012 as atividades do Totvs Labs, 55 unidade criada na região do Vale do Silício para desenvolver novos produtos em áreas como computação em nuvem, redes sociais, big data e mobilidade. $\mathrm{O}$ Banco do Brasil também instalou, em 2016, o Laboratório Avançado Banco do Brasil (Labb)56 no Vale do Silício. O objetivo é gerar inovações, assimilar e disseminar a cultura digital, identificar oportunidades para o banco, descobrirstartups e prospectar tecnologias em desenvolvimento porfintechs baseadas na região.

Por fim, tem sido criados ambientes de coworking para a comunidade de startups com a intenção de atrair suas ideias e projetos para um mesmo local e fomentar a articulação dos atores. Nesses espaços, convergem diferentes tipos de ações de apoio às startups, como programas de incubação, de aceleração, eventos e cursos.

Uma ação nesse sentido é o Cubo, 57 iniciativa do banco Itaú Unibanco com a Redpoint e.ventures, ${ }^{8}$ inaugurado em 2015. Seu objetivo é conectar empreendedores, investidores e empresas de diferentes setores oferecendo um espaço compartilhado para a permanência das startups e um ambiente com eventos, workshops, palestras e treinamentos. O banco não investe diretamente nas empresas, mas se mantém próximo de possíveis tendências e inovações a partir daquele ambiente.

Em 2016, foi inaugurado o Google Campus, ação da líder mundial em TI no âmbito de seu programa Google for Entrepreneurs.59 Nesse ambiente, é possível encontrar espaços de uso compartilhado, infraestrutura para realização de atividades, aceleração de startups e contato com investidores e mentores. Além disso, contempla o programa de residência do Google, que apoia startups de interesse estratégico da empresa. Além de São Paulo, existe em Londres, Madri, Seul, Tel Aviv e Varsóvia. 
Por fim, há o caso da empresa de telefonia Oi, que, em parceria com outras organizações, ${ }^{60}$ lançou o Programa de Incubação Oito, que, além de mentorias e de espaço de trabalho, fornece apoio gerencial, jurídico, financeiro e de comunicação e um aporte de até $\mathrm{R} \$ 150$ mil reais para estruturar o crescimento do negócio.

\section{APOIO PARA DESENVOLVIMENTO de NOVOS NEGócIOS E INICIATIVAS DE INVESTIMENTO DE RISCO}

Os espaços para desenvolvimento de novos negócios podem assumir diferentes modelos, destacando-se as incubadoras e as aceleradoras.

As incubadoras de empresas são atores importantes no apoio ao empreendedorismo iniciantee, ao longo dos últimos anos, apresentaram diferentes modelos: a primeira geração é caracterizada pela oferta de espaços e recursos compartilhados; a segunda, pela oferta de suporte, treinamento e mentoria; por fim, a terceira, além de apresentar as características das demais gerações, oferece redes tecnológicas, profissionais e financeiras. ${ }^{61}$ As incubadoras podem ser públicas, mais comuns desde os anos 1980, ou privadas, mais populares a partir dos anos 2000 , com o avanço da economia digital. $\mathrm{O}$ acesso rápido ao mercado eà rede de conhecimento se tornam elementos mais relevantes para as startups no século XXI, estimulando o nascimento de incubadoras privadas com foco em criar rapidamente novos negócios. ${ }^{62}$

Um exemplo é o programa de incubação do Grupo Algar, lançado em 2013, para apoiar o desenvolvimento das startups nas primeiras etapas de seus ciclos de vida. Além de oferecer espaço, a Algar fornece recursos técnicos e suporte financeiro na tentativa de fazer emergir empresas com potencial de crescimento.

Já as aceleradoras são um novo tipo de organização voltado a uma forma específica de apoio ao empreendedorismo. A aceleração é um processo interativo e dinâmico para startups por meio do fornecimento de recursos (financeiros e humanos) em etapas determinadas do desenvolvimento do empreendimento. ${ }^{63}$ Esse processo visa reduzir riscos e se baseia em treinamento e mentorias intensivos em um tempo curto e de duração limitada (de três a doze meses), no qual startups passam por uma competitiva seleção e compartilham o mesmo ciclo de desenvolvimento. O fim do ciclo em geral culmina em evento público que auxilia na captação de recursos financeiros, acesso a mercado e atração de parceiros, conhecido como "demo- day". ${ }^{64}$

Dentre os tipos possíveis de aceleradoras, ${ }^{65}$ as corporativas se destacam por fornecerem recursos das empresas para as startups atrelados a um ciclo de desenvolvimento definido. Essas ações buscam identificar novas tendências de serviços e produtos para um determinado [6o] Como Nokia, IBM, Oracle, Amazon Web Services, CPqD, Instituto Nacional de Telecomunicações (Inatel), Senai, Montaury Pimenta, Machado \& Vieira Mello, Oi Futuro, Yunus Negócios Sociais Brasil e Instituto Gênesis da PUC-Rio, responsável pela coordenação técnica.

[61] Garcia et al., 2015.

[62] Grimaldi; Grandi, 2005; Becker; Gassman, 2006; Chinsomboon, 2000.

[63] Dee et al., 2015; Pauwels et al., 2016; Bruneel et al., 2012; Clarysse; Wright; Van Hove, 2015.

[64] Miller; Bound, 2011; Baird; Bowles; Lall, 2013; Caley, 2013; Cohen; Hochberg, 2014; Cruz, 2014.

[65] Trataremos aqui em detalhes somente das aceleradoras corporativas em função do argumento principal do artigo. No entanto, é importante mencionar as aceleradoras independentes, o principal tipo. No Brasil, a partir de 2011, ganhou força o movimento de aceleração, e atualmente existem 41 ativas, tais como ACE, Artemísia, Baita, Darwin Starter, Liga Ventures, StartupFarm, Wow, Techmall, Cotidiano, Cesar. Labs e 85 Labs. O investimento estimado pelo conjunto das aceleradoras no país nas cerca de 1,1 mil startups ligadas a elas é de aproximadamente $\mathrm{R} \$ 50$ milhões (Abreu; Campos, 2016). 
[66] Clarysse; Wright; Van Hove, 2015.

[67] Dempwolf etal., 2015.

[68] Mais informações em: http:// wayra.co/br.

[69] Estratégia global da Telefónica com o objetivo de detectar, desenvolver e potencializar empreendedores e empresas de base tecnológica em diversas etapas do processo empreendedor. Mais informações em: https:// www.openfuture.org.

[70] Moreno, 2017. setor. Em virtude disso, os empreendimentos são selecionados de acordo com o interesse estratégico da corporação. ${ }^{66} \mathrm{Grande}$ parte dos recursos ofertados são oriundos da própria estrutura da organização, que provê sua rede de contatos e profissionais, além de potencializar a alavancagem das startups por meio da escala e rede de distribuição. ${ }^{67}$

Um exemplo é a Wayra, ${ }^{68}$ da Telefônica, primeira aceleradora corporativa a se estabelecer no país em 2012, integrante da estratégia global de conexão a startups da empresa: a Telefónica Open Future. ${ }^{69}$ Por meio de seus fundos e de seu programa de aceleração, a empresa já investiu 166 milhões $€$ em 1.532 startups no mundo entre 2011 e 2017. No Brasil, foram 58 empresas aceleradas no período, que receberam R\$ 9,2 milhões, atrás apenas de Espanha (567 startups), Chile (375) e Reino Unido (120 empresas).70 Outras seis empresas receberam $\mathrm{R} \$ 40$ milhões de fundos relacionados a Telefônica.

A partir de 2014, as empresas brasileiras começaram a adotar os princípios de aceleração como estratégia para identificar novos negócios. O Abril Plug and Play, promovido pela Editora Abril em parceria com a aceleradora americana Plug and Play Tech Center, foi uma das primeiras aceleradoras corporativas brasileiras.

Além das aceleradoras independentes e das aceleradoras corporativas, que têm espaços físicos separados de seus patrocinadores, as grandes empresas passaram a atuar fortemente também com programas de aceleração próprios, em geral realizados nas suas dependências ou em parceria com outras organizações.

Pelo lado das multinacionais, o Brasil passou a receber programas globais de aceleração, como é o caso da EDP Starter e da Oracle Cloud Startup Accelerator (Osca). O EDP Starter é um programa que surgiu em 2012 em Portugal, e sua primeira edição no Brasil foi em 2017, com o objetivo desenvolver startups em estágio bastante inicial. Já o Osca foi criado pela equipe de P\&D da Oracle e oferece seis meses de orientação de especialistas técnicos e de negócios, tecnologias avançadas, um espaço de coworking, acesso a clientes, parceiros e investidores, créditos livres para as soluções de Oracle Cloud, além de uma rede global em expansão composta por outras startups. Além de São Paulo, Bristol, Deli, Mumbai, Paris, Cingapura e Tel Aviv compõem a rede do programa.

Pelo lado nacional, o InovaBra, do Banco Bradesco, é um programa de atração de empreendedores para desenvolver soluções financeiras utilizando a infraestrutura do banco e os seus recursos humanos como mentores. As startups passam por um processo de seis meses para o desenvolvimento de um produto mínimo viável e sua experimentação. Desde a primeira edição em 2014, 1,6 mil empresas já foram avaliadas e vinte das selecionadas tiveram suas soluções integradas ao Bradesco. 
Também têm surgido no Brasil os programas de aceleração de modelos híbridos, envolvendo aceleradoras independentes e grandes empresas..$^{71}$ A Oxigênio, aceleradora da empresa Porto Seguro,,$^{72}$ iniciou suas atividades em conjunto com a Liga Ventures, 73 empresa responsável pelo programa de aceleração, e a Plug and Play.74 A Neogera, empresa criada pela empresa Intercement para gestão de portfólio de startups e projetos spin-off, e a Ace criaram um programa de aceleração especializado na construção civil com o intuito de identificar tanto empreendedores internos à Intercement como os externos. ${ }^{75}$

\section{CONCLUSÃO: DESAFIOS E OPORTUNIDADES \\ PARA EMPREENDEDORISMO E INOVAÇÃO NO BRASIL}

As novas dinâmicas da inovação no século XXI representam menos uma substituição das práticas do século XX do que um aumento de sua diversidade. Além disso, essas novas dinâmicas não devem ser vistas como resultados exclusivos das ações das startups, mas sim da coparticipação delas em arranjos diversos com outros atores. Entender o lugar das startups nesse contexto é importante para evitar considerá-las panaceia para o desafio da inovação e, assim, evitar equívocos, como cópia de políticas públicas e mesmo de ações privadas de outros países sem as devidas mediações para as condições institucionais, sociais e econômicas locais.

De qualquer modo,éclara a relevância crescente das startups, como se observa nas práticas tanto de governos como de empresas em direção ao apoio de empreendimentos nascentes inovadores.

Os esforços pela diversificação de políticas públicas em diferentes países do mundo, como o aumento das práticas de compartilhamento de risco e das chamadas "políticas relacionais" em vez de apenas financeiras. Isso aparece também em esforços regulatórios para criar normas para novas modalidades de investimento que vão surgindo na esfera do mercado, como o crowdfunding. Além disso, o interesse pelas startups por parte de governos se relaciona à sua capacidade de responder mais facilmente a demandas tecnológicas e soluções inovadoras para a sociedade, como fica patente nos chamados desafios tecnológicos.

O forte interesse por parte de grandes empresas em se associar a startups, usando para isso mecanismos variados de investimento de risco e de inovação aberta, também fica evidente com a profusão de casos internacionais e nacionais. A articulação é motivada pela capacidade das startups em renovar e arejar o sistema produtivo, nos diferentes setores (indústria, serviços, comércio e agricultura) e construir pontes nas cadeias produtivas (com clientes, fornecedores, institutos de pesquisa).
[71] Clarysse; Wright; Van Hove, 2015.

[72] Mais informações em: http:// www.portoseguro.com.br.

[73] Mais informações em: http:// liga.ventures.

[74] Mais informações em: http:// plugandplaytechcenter.com.

[75] Uma categoria de ação das grandes empresas que não vamos tratar diretamente neste artigo é o corporate venture capital, que se caracteriza mais por um investimento direto de recursos financeiros em startups para aquisições do que uma parceria propriamente dita. $\mathrm{O}$ movimento começa a ganhar força no Brasil. Em 2016, o Bradesco criou o InovaBra Ventures, que permite ao banco investir de $\mathrm{R} \$ 1$ a 5 milhões em startups de três áreas prioritárias do banco: algoritmos (que incluem big data e machine learning), plataformas digitais e blockchain. Na mesma linha, a Porto Seguro lançou o Porto Capital, braço de investimentos com $\mathrm{R} \$ 400$ milhões na busca de oportunidades em áreas como serviços financeiros, consumo, saúde, educação e tecnologia.Ambas as iniciativas complementam a estratégia das empresas de apoio a startups, o InovaBra e a Oxigênio, respectivamente. 
Nesses arranjos, as grandes empresas colaboram, por um lado, fornecendo conhecimento regulatório, de propriedade intelectual e de mercado; recursos financeiros; máquinas e equipamentos, de forma direta ou indireta; e estrutura técnica e para comercialização. Por outro lado, as pequenas empresas são as responsáveis por trazer novos conhecimentos, desenvolver tecnologias específicas e implementar novos modelos de negócios que, combinadas a uma estrutura adequada, podem levar a inovações de bens e serviços.

Os tipos de articulação passam por eventos temporários, como concursos e desafios, compartilhamento de recursos, com espaços destinados a conexão e formação, e apoio direto para a criação de novos negócios, com programas de aceleração e desenvolvimento de produtos e serviços em parceria. $O$ fato a ser observado é o interesse das grandes empresas em se articular às startups em busca de conhecimento novo, de solução de problemas ou de simplesmente entender que a articulação em um ecossistema em que circulam informações e oportunidades de inovação é um ativo importante a ser desenvolvido.

$\mathrm{O}$ apoio do setor privado ao empreendedorismo inovador no Brasil se disseminou, conforme mostram os inúmeros exemplos apresentados ao longo deste artigo. Mas, apesar das novas iniciativas e dos avanços crescentes em relação ao tema, o Brasil ainda precisa avançar nesse processo. Fatores como instabilidade de recursos, descontinuidade de programas e ausência de uma cultura de avaliação de resultados inibem a consolidação de uma política de Estado para inovação que tenha eficácia e eficiência. Desse modo, a implementação de ações públicas para startups se dá em um contexto mais instável do que em países como Coreia do Sul ou Israel, por exemplo.

Além disso, o mercado de capitais no Brasil ainda precisa avançar, uma vez que há poucos fundos nacionais corporativos dedicados ao investimento de al to risco e com foco em startups. Evidentemente isso se relaciona às condições macroeconômicas do país, com anos de juros muito altos, que inibem investimentos de risco.

Por fim, vale mencionar também o fato de as empresas brasileiras ainda pecarem na especificação de objetivos estratégicos dos programas, muitas vezes reproduzindo práticas de outras localidades que, não necessariamente, se ajustam às condições institucionais, culturais e legais do Brasil, como programas de aceleração sem objetivos claros ou para setores e produtos que exigem formatos distintos de apoio.

Apesar da diversificação do ambiente para inovação no Brasil, tanto em termos de políticas públicas como de ações privadas, ainda há um longo caminho a se percorrer em busca de resultados melhores, incluindo também aperfeiçoamentos no marco legal, no fortalecimento de uma indústria de capital risco e na interação entre ICTs e empresas, 
já que o desempenho brasileiro permanece insatisfatório nos indicadores de inovação, fraco tanto no número de startups brasileiras em rankings internacionais, quanto no de patentes depositadas, na sofisticação tecnológica das exportações ou no volume do investimento privado em $P \& D$.

CARLOS TORRES FrEIRE é doutor em Sociologia pela Universidade de São Paulo (USP) e pesquisador no Cebrap. O artigo é fruto de pesquisas que coordenou no Cebrap, para o qual contribuiu com o argumento principal, estrutura analítica e redação final.

Felipe MAsSAmi MARUYAma é mestrando em Engenharia de Produção na Escola Politécnica da USP e coordenador de Apoio ao Empreendedorismo Inovador da Secretaria Municipal de Inovação e Tecnologia de São Paulo.Fez parte da equipe de pesquisa sobre o tema no Cebrap, sendo responsável pela coleta e organização das informações e análise das práticas corporativas de articulação com startups.

MARCO POLLI é consultor em inovação, doutor em Política Científica e Tecnológica pelo DPCT/ Unicamp e analista da Finep. Contribuiu em projetos sobre o tema realizados no Cebrap, principalmente com análises sobre políticas de inovação e experiências internacionais.

\begin{tabular}{l} 
Recebido para publicação \\
em 30 de setembro de 2017. \\
\hline Aprovado para publicação \\
em 17 de outubro de 2017. \\
NOVOS ESTUDOS \\
CEBRAP \\
109, novembro 2017 \\
pp.51-76
\end{tabular}

\section{REFERÊNCIAS}

Abreu; Paulo R. M.; Campos, Newton M.Opanorama das aceleradoras de startups no Brasil. Fundação Getúlio Vargas. Create Space Independent Publishing Plataform, 2016.

Adner, Ron; Kapoor, Rahul. "Value Creation in Innovation Ecosystems: How the Structure of Technological Interdependence Affects Firm Performance in New Technology Generations". Strategic Management Journal,v.31, n. 3, mar. 2010, pp.306-333.

Agência Brasileira de Desenvolvimento Industria (ABDI); Fundação Getulio Vargas (FGV). Introdução ao private equity e venture capital para empreendedores: tudo que você precisa saber para buscaro investimento certo para seu negócio. São Paulo:ABDI, 2010.

Anokhin, Sergey; Wincent, Joakim; Frishammar, Johan. “A Conceptual Framework for Misfit Technology Commercialization". Technological Forecasting and Social Change, v. 78, n. 6, pp.1060-1071, jul. 2011.

Baird, Ross; Bowles, Lily; Lall, Saurabh. Bridging the "Pioneer Gap": The Role of Accelerators in Launching High-Impact Enterprises. ANDE; Village Capital, 2013.

Becker, Barbara; Gassmann, Oliver. "Corporate Incubators: Industrial R\&D and What Universities Can Learn from Them”. Journal of Technology Transfer, v.31, n.4, pp. 469-483, 2006.

Bruneel, Johan et al. The Evolution of Business Incubators: Comparing Demand and Supply of Business Incubation Services across Different Incubator Generations. Technovation, v. 32, n. 2, pp.110-121, fev. 2012.

Caley, Elizabeth. Seeding Success: Canada's Startup Accelerators. Ontario: MaRS Data Catalyst, 2013.

Chesbrough, Henry William. "Making Sense of Corporate Venturing Capital”. Harvard Business Review, v. 80, n. 3 , pp.90-97, mar. 2002 .

. Open Innovation. Cambridge: Harvard Business Press, 2003.

. Open Business Models. Cambridge: Harvard Business Press, 2006.

Chinsomboon, Oonut Mac. "Incubators in the New Economy". Dessertação (mestrado) - Sloan School of Management, Massachusetts Institute of Technology, Cambridge, 2000.

Clarysse, Bart; Wright, Mike; Van Hove, Jonas.A Look inside Accelerators:Building Businesses. Londres: Nesta, 2015.

Cohen, Susan G.; Hochberg, Yael V. “Accelerating Startups: The Seed Accelerator Phenomenon”. SSRN Journal, pp.1-16, mar. 2014 .

Coreia do Sul. Ministry of Strategy and Finance. “The Park Geun-hye Administration's Creative Economy Blueprint". Korea.net, 11 jun. 2013. Disponível em: http://www.korea.net/Government/Briefing-Room/ Press-Releases/view? articleId=2263. Acesso em: 1 fev. 2016.

Cruz, Edite.Acceleration Today:Trends \& Challenges. Lisboa: Beta-i, 2015

Dahlander, Linus; Gann, David M. “How Open Is Innovation?”. Research Policy, v.39, n. 6, pp. 699-709, jul. 2010. Dee, Nicola et al. Startup Support Programmes: What's the Difference? London: Nesta, 2015.

Dempwolf, C. Scott et al. Innovation Accelerators: Defining Characteristics among Startup Assistance Organizations. Small Business Administration, 2015. Disponível em: http://www.sba.gov/advocacy. Acesso em: 15 maio 2016.

Elder, Jakob. "Review of Policy Measures to Stimulate Private Demand for Innovation". Nesta Working Paper, n. 13/13, nov. 2013. Disponível em: https://www.nesta.org.uk/sites/default/files/review_of_policy_ measures_to_stimulate_private_demand_for_innovation._concepts_and_effects.pdf. Acesso em: 12 fev. 2016 . 
Elder, Jakob; Georghiou, Luke. "Public Procurement and Innovation: Resurrecting the Demand Side". Research Policy, v.36, n.7, Pp. 949-963, set. 2007.

Endeavor. Burocracia nos Negócios: os desafios de um empreendedor no Brasil. [S.1.], 2015. Disponível em: 〈https://www.cbinsights.com/reports/Unicorn-WhitePaper-2015.pdf〉.Acesso em 12 out. 2016.

European Commission. Growth:stimulating digitalentrepreneurship-initiative database. Luxemburgo: European Commission, 2016.

Financiadora de Estudos e Projetos (Finep). “A transformação da Finep: 2011-2014”. Publicação institucional. Rio de Janeiro: Finep, 2014.

. "Relatórios de gestão". Finep. Disponível em: http://www.finep.gov.br/acesso-a-informacao-externo/ transparencia/114-relatorios/relatorios-de-gestao.Acesso em: 24 out. 2016.

Garcia, Francilene Procópio et al. "Reference Center for Business Incubation: a proposal for a new model of operation Brazilian Associati on of Science Parks and Business Incubator". Anprotec, 2015.

Gassmann, Oliver; Enkel, Ellen. "Towards a Theory of Open Innovation: Three Core Process Archetypes". In: R\&D Management Conference, Lisboa, 2004. Proceedings... Lisboa: Radma, 2004.

Grimaldi, Rosa; Grandi,Alessandro. "Business incubators and newventure creation:an assessment of incubating models". Technovation, n.25, p.111-121, 2005.

HBS Alumni Angels of Brazil. Panorama do corporate venture no Brasil. 2017

Innovate UK. Sbri:Swindon Technology Strategy Board 2015. Swindon: Innovate UK, 2015.

InovAtiva Brasil. Disponível em: http://www.inovativabrasil.com.br/.Acesso em: 15 jun. 2016.

Isenberg, Daniel. The Entrepreneurship Ecosystem Strategy as a New Paradigm for Economy Policy:Principles for Cultivating Entrepreneurship. Babson Global, 2011.

Kantis, Hugo; Federico, Juan; Menéndez, Cecilia. "Políticas de fomento al emprendimiento dinámico en América Latina: tendencias y desafíos". CAF Working Papers, n. 9, ago., 2012.

Keating, Gina. Netflixed:The Epic Battle for America's Eyeballs. Nova York: Penguin, 2013.

Kohler, Thomas. "Corporate Accelerators: Building Bridges between Corporations and Startups". Business Horizons, v. 59, n.3, pp. 347-357, 2016.

Lardinois, Frederic. "Gmail Now Has More Than 1 B Monthly Active Users". Techcrunch, $1^{\circ}$ fev. 2016. Disponível em: https://techcrunch.com/2016/o2/o1/gmail-now-has-more-than-1b-monthly-active-users. Acesso em: $1^{\circ}$ fev. 2016.

Lerner,Josh.Boulevard of Broken Dreams:Why Public Efforts to Boost Entrepreneurship and Venture Capital Have Failed and What to Do About It. Princeton: Princeton University Press, 2009.

Lubik, Sarah; Ford, Simon; Despeisse, Mélanie. "Commercialising Advanced Material Processing Technology for Additive Manufacturing:The Case of Metalysis". Conference paper. R\&D Management Conference, Cambridge, 2016.

Lundvall, Ben. "National Innovation Systems:Analytical Concept and Development Tool". Industryand Innovation, v. 14, n. 1, pp. 95-119, 2007.

Malmberg, Anders; Maskell, Peter. “Towards an Explanation of Regional Specialization and Industrial Agglomeration”. European Planning Studies, v. 5, v. 1, pp. 25-41, 1997.

Malecki, Edward J.; Nijkamp, Peter. “Technology and Regional Development: Some Thoughts on Policy”. Environment and Planning C: Government and Policy, v. 6, n. 4, pp.383-399, 1988.

Marceau, Jane. "Why Can't We All Have a Silicon Valley?".Australian Review of Public Affairs, 12 dez.2005. Disponível em: http://www.australianreview.net/digest/2005/12/marceau.html.Acesso em: 22 ago. 2017.

Marques, Fabrício. "Pipe 20 anos". Pesquisa Fapesp, n. 257, pp. 32-37, jul. 2017. Disponível em: http://revistapes quisa.fapesp.br/wp-content/uploads/2017/07/032-037_pipe_257_novo.pdf. Acesso em: $1^{\circ}$ jul 2017.

Mason, Colin; Brown, Ross. "Entrepreneurial Ecosystems and Growth Oriented Entrepreneurship". Entrepreneurial Ecosystems and Growth Oriented Entrepreneurship Workshop, Haia, 2013. Disponível em: http:// www.oecd.org/cfe/leed/entrepreneurial-ecosystems.pdf.Acesso em: 15 jan. 2016.

Miller, Paul; Bound, Kirsten. The Startup Factories: The Rise of Accelerator Programmes to Support New Technology Ventures. Londres: Nesta, 2011.

Minshall, Tim et al. "Making 'Asymmetric' Partnerships Work". Research Technology Management, v. 53, n. 3 , pp. 53-63, 2010.

Mocker, Valerie; Bielli, Simona; Haley, Christophe. Winning Together:A Guide to Successful Corporate-startup Collaborations. Londres: Nesta, 2015.

Moreno, Felipe. “Telefónica investe em 1.532 startups ao redor do mundo e lucra R $\$ 135$ milhões". StartSe, 16 jan. 2017. Disponível em: https://conteudo.startse.com.br/mercado/felipe/telefonica-investe-em-1-532-startups-ao-redor-do-mundo-e-lucra-r-135-milhoes. Acesso em: 8 nov. 2017.

Mowery, David C. “Defense-related R\&D as a Model for 'Grand Challenges' Technology Policies”. Research Policy, v.41, n.10, pp.1703-1715, dez.2012.

Organisation for Economic Co-operation and Development (OECD). Demand-side Innovation Policies. Paris: OECD, 2011. Disponível em: https://goo.gl/59Zjoc. Acesso em:31 jul. 2016. .OECD Science, Technology and Industry Outlook 2012. Paris: OECD, 2012. Disponível em: https://goo.gl/PRLNPU.Acesso em: 4 dez. 2015.

. Development Centre Studies. Startup Latin America: Promoting Innovation in the Region. Paris: OCDE, 2013. Disponível em: https:/www.oecd.org/dev/americas/Eng_complete\%2oStart\%2oUp\%2oLatin\%2o America\%2opocket\%2oedition.pdf.Acesso em: 5 de mar. 2016 . 
. OECD Science, Technology and Industry Outlook 2014. Paris: OECD, 2014. Disponível em: https://goo.gl/ yW9vPO.Acesso em: 4 dez. 2015.

. Entrepreneurship at a Glance. Paris: OECD, 2015. Disponível em: http://www.oecd-ilibrary.org/industry-and-services/entrepreneurship-at-a-glance-2015_entrepreneur_aag-2015-en. Acesso em: 13 jun. 2016. .Financing SMEs and Entrepreneurs 2016:An OECD Scoreboard. Paris: OECD, 2016. Disponível em: https://goo. $\mathrm{gl} / \mathrm{vkmT6F}$. Acesso em: 15 jun. 2016

Oster, Shai; Chen, Lulu Yilun. “Inside China's Historic \$338 Billion Tech Startup Experiment”. Bloomberg Tecnology, 8 mar.2016.Disponível em:https://www.bloomberg.com/news/articles/2016-03-08/china-state-backed-venture-funds-tripled-to-338-billion-in-2015. Acesso em: 19 jun. 2016.

Osterwalder, Alexander; Pigneur, Yves. Business model generation: inovação em modelos de negócios: um manual para visionários, inovadores e revolucionários. Rio de Janeiro: Alta, 2011.

Pauwels, Charlotte et al. "Understanding a New Generation Incubation Model: The Accelerator". Technovation, v. 50-51, pp. 13-24, abr.-maio 2016.

Plagge, Arnd. Public Policy for Venture Capital. Nova York: Springer, 2006.

Poncet, Christian. "Venture Capital and Small Business". In: Carayannis, Elias G. (Org.).Encyclopedia of Creativity, Invention, Innovation and Entrepreneurship. Nova York: Springer, 2013.pp. 1877-1885.

“Resultados do Sinapse em SC". Sinapse da Inovação. Disponível em: https://goo.gl/attMih.Acesso em: $1^{\circ}$ jun. 2016.

Rieche, Fernando Ceschin; Faria, Lívia Ribeiro Borges de. "O corporate venturing como alternativa de apoio à inovação: motivações e benefícios". Revista do BNDES, n. 41, pp. 379-413, jun. 2014.

Ries, Eric. "What Is a Startup?". Startup Lessons Learned, 21 jun. 2010 . Disponivel em: http://www.startuplessons learned.com/2010/o6/what-is-startup.html. Acesso em: 5 mar. 2016.

Sampat, Bhaven N. "Mission-oriented Biomedical Research at the NIH". Research Policy, v.41, n. 10, pp.1729-1741, dez. 2012.

Saxenian, AnnaLee. Regional Advantage: Culture and Competition in Silicon Valley and Route 128. Cambridge: Harvard University Press, 1994.

Schrank, Andrew. "Beyond the Silicon Valley Consensus". Conferência na Escuela de Gobierno y Transformación Pública, Tecnológico de Monterrey, Cidade do México, México, 23 jun. 2017.

Startup Europe Partneship. “Sep Monitor: Scale Up Portugal”. European Comission, jun.2017.

Spender, John-Christopher et al. "Startups and Open Innovation: A Review of the Literature". European Journal of Innovation Management, v. 20, n. 1, pp. 4-30, 2017.

Startup Portugal.Agência para a Competitividade e a Inovação. Disponível em: https://goo.gl/iqJWD3. Acesso em: $1^{\circ}$ jun. 2016.

Storper, Michael. The Regional World: Territorial Development in a Global Economy. Nova York: Guilford, 1997.

Storper, Micheal; Venables, Anthony J. "Buzz: Face-to-face Contact and the Urban Economy”. Journal of Economic Geography,v.4, n.4, pp.351-370, ago. 2004.

Teece, David J.; Pisano, Gary; Shuen, Amy. “Dynamic Capabilities and Strategic Management”. Strategic Management Journal,v.18, n. 7, Pp. 509-533, ago.1997.

Torres-Freire, Carlos; Maruyama, Felipe Massami; Polli, Marco. "Políticas públicas e ações privadas de apoio ao empreendedorismo inovador no Brasil: programas recentes, desafios e oportunidades”. In: Turchi, Lenita; Morais, José Mauro de (Orgs.). Políticas de Apoio à Inovação Tecnológica no Brasil. Brasília: Ipea, 2017.

Tredgett, Emma; Coad, Alex. The Shaky Start of the UK Small Business Research Initiative (Sbri) in Comparison to the US Small Business Innovation Research Programme. London: Birkbeck University of London, 2015.

Vanhaverbeke, Wim; Chesbrough, Henry William. "A Classification of Open Innovation and Open Business Models". In: Chesbrough, Henry William; Vanhaverbeke, Wim; West, Joel (Orgs.). New Frontiers in Open Innovation. Oxford: Oxford University Press, 2014.pp.50-68.

Weiblen, Tobias; Chesbrough, Henry William. "Engaging with Startups to Enhance Corporate Innovation". California Management Review, v. 57, n. 2, pp. 66-90, 2015.

West, Joel. “Challenges of Funding Open Innovation Platforms: Lessons from Symbian Ltd”. In: Chesbrough, Henry; Vanhaverbeke, Wim; West, Joel (Orgs.). Oxford: Oxford University Press, 2014. pp. 29-49.

West, Joel; Bogers, Marcel. "Leveraging External Sources of Innovation: A Review of Research on Open Innovation”. Journal of Product Innovation Management, v. 31, n. 4, pp. 814-831, jul. 2014.

World Bank. Doing Business: Comparing Business Regulation for Domestic Firms in 189 Economies.13a ed. Washington: World Bank, 2016.Disponível em: http://www.doingbusiness.org/ /media/GIAWB/Doing\%2oBusiness/ Documents/Annual-Reports/English/DB16-Full-Report.pdf.Acesso em: 6 dez. 2016.

World Economic Forum. Collaborative Innovation: Transforming Business, Driving Growth. Genebra: World Economic Forum, 2015.

YCombinator. Disponível em: https://www.ycombinator.com. Acesso em: 15 jul. 2016.

Zacharakis,Andrew L.;Shepherd,Dean A.; Coombs,Joseph E. “The Development of Venture-capital-backed Internet Companies:An Ecosystem Perspective". Journal of Business Venturing, v.18, n. 2, pp. 217-231, mar. 2003. 